\title{
The Impact of an Internet Use Promotion Programme on Communication, Internet Use, and the Extent of Social Networks among Low-Income Older Adults
}

\author{
Jinsook Kim ${ }^{1}$ (D) Jennifer A. Gray ${ }^{1}$ - James R. Ciesla ${ }^{2}$. Ping Yao ${ }^{1}$
}

Accepted: 8 July 2021 /Published online: 21 July 2021

(C) The Author(s), under exclusive licence to Springer Science+Business Media, LLC, part of Springer Nature 2021

\begin{abstract}
We examined whether an internet use promotion intervention influences low-income older adults' communication modes, internet use, and social networks using existing data collected for an intervention. Participants living in public senior housing facilities in the United States $(n=77)$ completed surveys before and after a 12 -week computer and internet training. The six-item Lubben Social Network Scale (LSNS6) was used to measure the extent of older adults' social networks. The primary mode of communication shifted from more traditional means to internet-based communications ( $p<.0005$ in a Fisher's exact test). The frequency of internet use significantly increased ( $p<.00005$ in a one-sided Sign test). Overall, the LSNS-6 score increased by 4.1 points ( $p<.00005$ in a Welch's t-test). The LSNS-6 score increase was significantly larger among African Americans than Whites, controlling for gender $(p<.05$ in negative binomial regression). Moderate $(p<.005)$ and frequent internet users $(p<.05)$ had higher LSNS-6 scores than rare internet users at posttest when gender and race were controlled for in linear regression. Comparatively more improvement in the extent of social networks among African Americans suggests greater benefits of such interventions for population groups of disadvantaged backgrounds. Larger social networks among moderate and frequent internet users than rare users suggest positive impacts of internet communications on social networks.
\end{abstract}

Keywords Older adults $\cdot$ Internet use $\cdot$ Intervention $\cdot$ Social networks $\cdot$ Programme evaluation

Though the importance of developing and maintaining good social networks increases with age (Nahm \& Resnick, 2001; Nahm et al., 2004), older adults are increasingly likely to become socially isolated as their social networks decrease due

Jinsook Kim

jkim4@niu.edu

Extended author information available on the last page of the article 
to various factors, including the death of families and friends, disability, reduced mobility, and geographic relocation (Livingston, 2019; Mellor et al., 2008; Nahm \& Resnick, 2001; Nahm et al., 2004). The internet can help older adults improve their social networks by circumventing some restrictions in communication (Aggarwal et al., 2020; Choi et al., 2012; Woodward et al., 2011). During the COVID-19 pandemic, however, many older adults have experienced both digital and social exclusions, since their lack of access to and skill with digital technologies has increased their social isolation (Seifart et al., 2021).

Social networks have been used as a measure of social connectedness, in the sense that social networks allow for the provision of social support (Coreil, 2010). Social isolation is a related concept that is the opposite of social connectedness. Social isolation refers to the absence of contact with other people, social support, or social connectedness (Hawthorne, 2006). Lubben defined social networks as both family and friends, with whom one could connect, utilizing different types of social support (Lubben, 1988; Lubben et al., 2006). With Lubben's social network measures, individuals with social networks that are smaller than a cutoff point are considered socially isolated (Lubben et al., 2006). In this study, we refer to the extent of social networks based on Lubben's work (Lubben, 1988; Lubben et al., 2006).

Although older adults are less likely than their younger peers to engage in computer and internet usage (Anderson \& Perrin, 2017; Macdonald \& Hulur, 2021; Zickuhr \& Madden, 2012), such technological skills can be learned and adopted (Rosenthal, 2008; Sayago et al., 2013; Winstead et al., 2013). Many computer and internet intervention programmes have been shown to positively influence participants' social networks or social connectedness (Aggarwal et al., 2020; Chen \& Schulz, 2016; Gardiner et al., 2018; Ibarra et al., 2020).

In this paper, we review the literature on internet use among older adults and the effect of intervention programmes on older adults' internet use and social networks. Building upon the literature, we evaluate the impact of a computer/internet training programme on communication, internet use, and social networks using data collected from low-income older adults in the United States. including racial minorities.

\section{Digital Divide}

Studies have shown that a digital divide exists by age, in that older adults are less likely to use computers and the internet than younger adults (Anderson \& Perrin, 2017; Smith, 2014b; Zickuhr \& Madden, 2012; Zickuhr \& Smith, 2012). In 2018, approximately 90 percent of all adults in the United States used the internet, as compared to 66 per cent of those ages 65 and older (Pew Research Center, 2018). The divide appears to increase further in senior years, with those 70 and older involved in even less computer and internet activity (Friemel, 2016). This is a problem not only for older adults having physical access to technology, but also their attitudes and acceptance of such technologies, as well as their skill levels in using it (Broady et al., 2010; Chen \& Chan, 2011).

The depth and breadth of computer and internet usage also seems to differ by age. Older adults tend to have more limited expectations and goals compared to 
younger adults (Loges \& Jung, 2001) and use fewer computer and internet applications than their younger peers (Carpenter \& Buday, 2007; Czaja \& Lee, 2007; Gatto \& Tak, 2008; Loges \& Jung, 2001). The reasons for this difference include cognitive decline (der Wardt et al., 2012) and concerns about the risks of being online (Kim \& Gray, 2016; White et al., 2017).

In addition to age, a digital divide has been found to exist by other demographic factors (Anderson \& Perrin, 2017; Choi \& DiNitto, 2013; DiMaggio et al., 2004; Grossman et al., 2019; Smith, 2014a; Werner et al., 2011; Yoon et al., 2020; Zickuhr \& Smith, 2012). Older adults in the United States who have an average household income of at least $\$ 75,000$ or more and those who are college graduates are more likely to use the internet than their poorer and less educated peers (Anderson \& Perrin, 2017; Smith, 2014a, b). A Swedish study (Olsson et al., 2019) reported a similar pattern where more resourced older adults in terms of income and education used a broader array of online platforms and devices with greater frequency.

Digital divides by race and ethnicity also exist (DiMaggio et al., 2004; Lorence et al., 2006; Smith, 2014a; Werner et al., 2011). Among all U.S. adults, internet use was 87 per cent among Whites and 80 per cent among Blacks in 2013 (Smith, 2014a). The digital divide by race is larger among older adults than the general adult population (Mitchell et al., 2019; Werner et al., 2011). In 2013, 63 per cent of White older adults compared to 45 per cent of Black counterparts used the internet, and 51 per cent of White compared to 30 per cent of Black older adults had broadband at home (Smith, 2014a).

\section{Impacts of Intervention Programmes on Computer and Internet Usage}

Computer and internet training for older adults has shown that it can assist them in using the computer and internet more regularly for communication purposes, which can serve to decrease the digital divide (Bertera et al., 2007; Damnee et al., 2019; Fields et al., 2020; Ma et al., 2020; Woodward et al., 2011; Xie \& Bugg, 2009). In a randomized field trial for older adults (60 years and older) of a 6-month computer and internet training programme (Woodward et al., 2011), participants in the experimental group demonstrated improvements in computer usage self-efficacy. They also used a greater number of information and communication technologies, including the internet and email (Woodward et al., 2011). A tablet-PC training intervention with 13 community-based older adults through 10 sessions over a 5-month period demonstrated statistically significant improvements in participants' internet and information communication technology acceptance and skills (Damnee et al., 2019). In an in-home technology training programme in which tablets, broadband, and individualized training were provided to socially isolated older adults (Fields et al., 2020), participants were randomized into the treatment $(n=44)$ and waitlist $(n=39)$ groups. Results showed that the intervention group demonstrated statistically significant improvements in technology use, and marginally significant improvements in technology confidence and social support (Fields et al., 2020). 
Despite the diversity of the older population in the United States (Mather et al., 2015; Mather et al., 2019), older adults from disadvantaged backgrounds are less likely to be included in computer and internet-related interventions and evaluation studies (Kim, 2008). Besides a few exceptions (Bertera et al., 2007; Campbell, 2008; Fields et al., 2020; Jung et al., 2010), most computer and internet-related evaluation studies on non-institutionalized older adults in the United States have been conducted with more resourced populations (Kim, 2008). Participants in evaluated programmes tend to be well educated or overwhelmingly White (Berkowsky et al., 2013; Billipp, 2001; White et al., 2002). Since older adults from disadvantaged backgrounds tend to have additional barriers to internet use, including less access to the internet, low literacy, less experience with technology, limited financial resources, and disabilities (Choi \& DiNitto, 2013; Kaye, 2000; Kim, 2008), the impact of training programmes on computer and internet use for disadvantaged populations may be different from that for their more well-resourced counterparts.

\section{Impacts of Internet Training on Social Networks}

One of primary objectives of internet training interventions is to improve older adults' social wellbeing through various mechanisms including expansion of social networks or improvement of social connectedness (Chen \& Schulz, 2016; Gardiner et al., 2018; Ibarra et al., 2020). The literature indicates positive impacts of such interventions on social connectedness in general (Banbury et al., 2017; Czaja et al., 2018; Isaacson et al., 2019; Morton et al., 2018; Neves et al., 2019). In randomized controlled trials, interventions involving internet training reduced social isolation (Czaja et al., 2018) and increased social network activities (Morton et al., 2018). In uncontrolled pre-posttest design studies using video conferencing techniques, the mean number of network members increased (Banbury et al., 2017) and the size of social networks expanded (Isaacson et al., 2019) post intervention among community dwelling older adults. Qualitative data from a small sample of retirement home residents (Neves et al., 2019) indicated increased interactions with family and friends in general and an increase in social connectedness among participants with relatives living in distant locations.

Alternatively, other studies demonstrated no significant improvement in social networks or social connectedness after an intervention (Mellor et al., 2008; Myhre et al., 2017; Slegers et al., 2008). A study with community dwelling older adults (Slegers et al., 2008) found that internet and computer training did not have significantly consistent effects on social network development when measured 4 and 12 months post training. Similarly, in another study (Mellor et al., 2008), twenty older adults from a retirement village in a computer and internet training programme did not demonstrate improvement in social connectedness 12 months after the training. An intervention with participants from two 
retirement communities (Myhre et al., 2017), showed no improvement in social connectedness after participating in 3-session Facebook trainings.

\section{Impacts of Internet Use on Social Networks and Psychological Wellbeing}

Two main theses that explain how online interactions affect social networks and psychological wellbeing are the social augmentation and social displacement theses (Bessière et al., 2008). The social augmentation thesis posits that internet communications strengthen social resources by providing an additional channel for social interactions and expanded social networks (Bessière et al., 2008; Boase et al., 2006; Quan-Haase et al., 2005; Wellman et al., 2001). Multiple studies support this perspective. A study using cross-sectional data from older adults of European countries (Lelkes, 2013) indicated that internet contact did not crowd out in-person social contact. The study also suggested that the most disadvantaged groups may benefit the most from internet use. Internet use among older adults with lower education was associated with a greater decrease in social isolation than among those with higher education, although the same association was not found with respect to income groups (Lelkes, 2013). Another cross-sectional study using data from U.S. adults (Boase et al., 2006) found that emails did not substitute or replace other forms of contact such as in-person and phone contact in maintaining social ties. Instead, as emails were used to contact a higher percentage of significant social ties, all other means of communication, including phone and in-person contact, were used at a higher percentage (Boase et al., 2006). A survey with North American adults (Wellman et al., 2001) demonstrated that online interactions supplemented face-to-face and telephone communication without affecting it either positively or negatively. Moreover, more internet activities were associated with increased offline participation in voluntary organizations and political activities (Wellman et al., 2001). More recent studies demonstrated positive effects of internet use and digital communication on social connectedness and loneliness without decreasing other forms of social contact (Burholt et al., 2020; Yu et al., 2021). In a cross-sectional study with community dwelling older adults in the United Kingdom, the degree of social isolation among those with infrequent face-to-face contact with relatives decreased if text or email communications were used more frequently (Burholt et al., 2020). A longitudinal study with a nationally representative sample of U.S. older adults found that internet use was related to decreased loneliness (Yu et al., 2021). Over 8 years, the overall frequency of social contact with people in their social networks did not decrease among internet users while it decreased among non-internet users (Yu et al., 2021).

The social displacement thesis, on the other hand, suggests that the psychological wellbeing of internet users deteriorates as internet communications displace other forms of social interactions (Kraut et al., 1998; Nie, 2001; Shklovski et al., 2004). In a longitudinal study, greater internet use was associated with decreased family communication and more limited social networks, as well as 
increases in depression and loneliness (Kraut et al., 1998). Another study using longitudinal data (Shklovski et al. 2004) also demonstrated a negative impact of internet use on in-person interactions regardless of the measures of internet use (the frequency of use, the breadth of use, and number of years of internet use). The social displacement thesis appears to be in accord with research findings that indicate lower-quality psychological values of online social interactions compared to those from in-person interactions; and a lack of strong ties or enduring social support from online interactions (Bessière et al., 2008; Cummings et al., 2002; Weiser, 2001).

Evidence also suggests that internet use does not have the same effect on social and psychological wellbeing (Bessière et al., 2008; Kraut et al., 2002; Nakagomi et al., 2020; Szabo et al., 2019). Whether internet use leads to social augmentation or displacement may depend on the purpose of use, personality, and the initial social resources of the user (Bessière et al., 2008; Kraut et al., 2002; Nie \& Hillygus, 2002; Shklovski et., al. 2004). Internet use for communication with friends and family was associated with decreased depression or social loneliness (Bessière et al., 2010; Nakagomi et al., 2020; Sum et al., 2008; Szabo et al., 2019) while informational (e.g., finding health-related information) and instrumental uses (e.g., banking) did not have such positive associations (Nakagomi et al., 2020; Szabo et al., 2019) or were associated with negative outcomes such as depression (Bessière et al., 2010). A longitudinal study of those using the internet for communication showed improved psychological wellbeing among extroverts and individuals with more social support (Kraut et al., 2002). Increased internet use, however, had a negative effect on social and psychological wellbeing among introverts and those with less social support (Kraut et al., 2002). A large panel study on the association of internet use among retired older adults, however, indicated the largest reduction of depression among older adults who were living alone than those who were living with someone (Cotten et al., 2014).

Research evidence of the effect of internet use on social connectedness and psychological wellbeing is inconclusive due to methodological limitations, inconsistency in outcomes and interpretations, and a lack of representativeness and long-term effects (Choi et al., 2012; Dickinson \& Gregor, 2006; Forsman \& Nordmyr 2017; Gardiner et al., 2018; Ibarra et al., 2020; van der Wardt et al., 2012; Wagner et al., 2010). This study therefore evaluates whether participation in a computer/internet training programme influences social networks of low-income older adults including racial minorities using a validated social network measure.

The aim of this study was to examine: (a) whether internet use affects the extent of social networks among low-income older adults; and (b) whether the changes in the extent of social networks vary by demographic characteristics.

\section{Methods}

\section{Study Design}

This study used existing data collected for an intervention with a one-group-preand-post design. The authors conducted a post hoc evaluation without involvement 
in study design or data collection. The data were collected from participants before and after a 12-week computer and internet training programme conducted in a US Midwestern location. Participants completed a pretest before the training and a posttest within a month after completion of the training. Upon completion of the training, participants received a free laptop computer for their individual use. The training was part of a pilot intervention programme designed to address multiple barriers to computer and internet use among low-income older adults and people with disabilities living in public senior housing facilities. It provided public computer stations in a computer lab and Wi-Fi access in common areas in the buildings as the intervention started. Three levels of computer and internet skills training (beginner, intermediate, and advanced) were offered based on an initial proficiency test. The training was delivered in a one-hour session per week over the course of 12 weeks and was designed to accommodate participants with various needs including those with low literacy and educational levels. Written lessons, which were projected on a screen in the computer learning center, began with very basic computer skills and advanced to higher-level skills.

\section{Participants}

Seventy-seven low-income older adults completed questionnaires both before and after a 12-week computer and internet skills training programme. The participants were from 12 multi-unit public housing buildings. The research protocol and consent process were reviewed and approved by the university institutional review board. Prior to administration of the baseline survey, the purposes of the study and the procedures involved in participation were explained, and informed consent was obtained.

\section{Instrument}

The hard copy, self-administered questionnaire included questions on demographic characteristics, prior experience with computers and the internet, current computer ownership and access to the internet, communication modes, internet use, and social networks.

The primary mode of communication with relatives and friends included four response categories: face-to-face/in-person visits, mail, phone, and email/internet. Response choices for the frequency of internet use were rarely/never, once per month, once per week, several times per week, once per day, and several times per day.

An abbreviated version of the Lubben Social Network Scale (LSNS-6) (Lubben \& Gironda, 2000) was used to measure the extent of older adults' social networks. The LSNS-6 includes questions on the number of relatives and friends one sees or hears from at least once per month, feels close enough to call on for help, and feels at ease enough to talk about private matters. The 6 questions have the following 6-point Likert-type response choices: $0=$ none, $1=$ one, $2=$ two, $3=$ three or four, $4=$ five 
through eight, and $5=$ nine or more. The sum of 6 item scores (ranging from 0 to 30) is used to measure the extent of overall social networks (Lubben et al., 2006). A person with a LSNS-6 score less than 12 is considered socially isolated (Lubben et al., 2006). The LSNS-6 is known to have good validity and reliability in validation studies (Chang et al., 2018; Jang et al., 2020; Myagmarjav et al., 2019; Sansoni et al., 2010). Rasch and classical factor analyses using data from the same sampling pool demonstrated an adequate performance of the LSNS-6 as an overall measure of social networks in community-residing older adults (Gray et al., 2016).

Hypotheses Based on the social augmentation thesis (Boase et al., 2006; Quan-Haase et al., 2005; Wellman et al., 2001) and existing empirical research (Lelkes, 2013), the following hypotheses were tested.

Hypothesis 1: The extent of participants' social networks increases between the pretest and the posttest.

Hypothesis 2: More frequent internet use is associated with more extensive social networks among participants.

Hypothesis 3: Social networks improve to a larger extent among participants with less resources, such as those with lower education and income and racial minorities.

Hypotheses 1 and 2 are based on the social augmentation thesis that the extent of social networks expands as internet communication is added to other forms of social interactions (Boase et al., 2006; Quan-Haase et al., 2005; Wellman et al., 2001). Hypothesis 3 is based on a study finding that the most socially disadvantaged older adult groups benefited the most from internet use (Lelkes, 2013).

\section{Analysis}

Sample characteristics and the distribution of variables were examined, using a mean, standard deviation, and a range for a continuous variable and percentages and Fischer's exact tests for discrete variables (Mehta \& Patel, 1983). The main variables of interest were the primary mode of communication (4 categories), the frequency of internet use (3 categories), and the LSNS-6 total score.

Internet use frequencies were recategorized from the original six groups into three (rare use $=$ rarely/never or once per month; moderate use $=$ once per week or several times per week; and frequent use = once per day or several times per day) to reduce the cells with no observations. Given the presence of five or fewer cases in some cells, a Fisher's exact test was used to examine the differences in communication mode and internet use frequency by gender, age, race, education, and income group at each pretest and posttest.

The difference in the extent of social networks (measured by the LSNS-6 total score) by demographic characteristics, primary mode of communication, and internet use frequency was investigated using a t-test or analysis of variance (ANOVA) for each pretest and posttest score. The LSNS-6 total score at each pretest and posttest was normally distributed as indicated by the Shapiro-Wilk 
normality test $(p>.05)$ (StataCorp, 2011a). When the groups compared had unequal variances, the Welch's t-test (Ruxton, 2006) was also used. The Welch's t-test can be used in place of the usual (Student's) t-test for variables with a normal distribution but with unequal variances between groups (Ruxton, 2006). The Welch's t-test is superior to the Student's t-test when there are extreme discrepancies in sample sizes and variances between two groups and the total sample size is small (e.g., less than 30) (Zimmerman, 2004). The Welch's t-test does not pool variances in computation of an error term and alters the degree of freedom to prevent inflated Type I error and stabilize Type II error (Zimmerman, 2004).

The pre-post difference in primary mode of communication was tested using a Fisher's exact test. A pre-post difference in the frequency of internet use was examined using a Sign test for matched pairs. The non-parametric test compares scores of matched or paired samples (e.g., pre and post observations of individuals) without requiring the outcome's distribution to be normal or symmetric (Hald, 2003). The Sign test produces the results of three hypothesis tests: whether the median of the differences between paired observations is positive, negative, and zero (StataCorp, 2011a). The pre-post difference in the LSNS-6 total score was examined using both paired t-test and Welch's t-test because of the unequal variances of the pretest and posttest scores (Hypothesis 1). An effect size was examined to determine practical significance of the change in LSNS-6 score between pre- and posttests using Glass's Delta (Ialongo, 2016; Maher et al., 2013). In addition, the pre-post difference in the LSNS-6 total score was examined for each demographic subgroup using a paired t-test for groups with equal variances and a Welch's t-test for groups with unequal variances.

ANOVA was used to test whether the LSNS-6 total score differs by internet use frequency at each pretest and posttest (Hypothesis 2). LSNS-6 total scores had equal variance between internet use frequency subgroups at each pretest and posttest indicated by Bartlett's test $(p>.05)$. When an ANOVA result was significant, the Bonferroni and Scheffé tests (Savin, 1980) were used to identify specific pairs of categories that were statistically different from one another. Linear regression was used to examine whether an association between the internet use frequency and LSNS-6 total score remains the same when demographic variables were controlled for.

In examining the change in the extent of social networks, negative binomial regression was used because the changes in the LSNS-6 total score between the pretest and the posttest were not normally distributed and skewed to the right. Between two alternative regression models for this type of distribution, Poisson and negative binomial regression, the latter was found to be better. A likelihood ratio test of the overdispersion parameter alpha showed that negative binomial regression was more appropriate for the data than Poisson regression $(p<.01)$ (Long \& Freese, 2001). Simple negative binomial regression was used to examine whether the change in the LSNS-6 total score between the pretest and the posttest varies by each education (less than high school, high school diploma, and more than high school), income (annual income at least $\$ 5000$ or not) and race (African American or not) (Hypothesis 3). Multiple negative binomial regression was used to examine whether a significant association between an independent variable and the change in the LSNS-6 
total score holds when another demographic variable is controlled for. All analyses were performed using Stata version 12 (StataCorp, 2011b).

\section{Results}

\section{Sample Characteristics}

Table 1 presents the participants' socio-demographic information and computer and internet use experience. The majority of the sample was female $(63.6 \%)$ with a mean age of 73.8 (ranging from 65 to 91 years). One quarter (24.7\%) was African American with the remainder being White. Over one quarter of the sample had obtained a high school degree or equivalent (28.6\%), and over one third

Table 1 Sample Characteristics $(n=77)$

\begin{tabular}{lllr}
\hline & & $n$ & $\%$ \\
\hline Gender & Female & & \\
& Male & 49 & 63.6 \\
& Missing & 27 & 35.1 \\
& & 1 & 1.3 \\
Race & White & & \\
& African-American & 58 & 75.3 \\
& & 19 & 24.7 \\
Age & & & \\
& $65-69$ & 26 & 33.8 \\
& $70-79$ & 33 & 42.9 \\
& $80+$ & 18 & 23.4
\end{tabular}

Education

$\begin{array}{lll}<\text { High school } & 29 & 37.7 \\ \text { High school or equivalent } & 22 & 28.6 \\ \text { Some college+ } & 26 & 33.8\end{array}$

Income

$\begin{array}{lll}<\$ 5000 & 19 & 24.7 \\ \$ 5000-\$ 15000 & 41 & 53.2 \\ \$ 15001+ & 9 & 11.7 \\ \text { Missing } & 8 & 10.4\end{array}$

Prior computer use

$\begin{array}{llr}\text { Yes } & 26 & 33.8 \\ \text { No } & 44 & 57.1 \\ \text { Missing } & 7 & 9.1\end{array}$

Prior Internet use

\begin{tabular}{llr} 
Yes & 39 & 50.6 \\
No & 34 & 44.2 \\
Missing & 4 & 5.2 \\
\hline
\end{tabular}

${ }^{\text {a }}$ Mean age $=73.8$. Standard deviation $=6.8$. Range: $65-91$ 
(33.8\%) had completed some college or higher education. Since the participants resided in public housing facilities, the income distribution was relatively homogenous with almost 8 out of 10 earning $\$ 15,000$ or less. At pretest, 33.8 per cent reported ever using a computer, and 50.6 per cent ever using the internet.

\section{Communication-related Variables}

Table 2 presents the distributions of computer ownership, internet access, the primary mode of communication, and the frequency of internet use at pretest and posttest. Computer ownership and internet access increased from 74 to 97.4 per cent and from 48 to 70.1 per cent respectively between pre and posttest. The primary mode of communication with relatives was similar across demographic groups at each pre and posttest (results not shown). The primary mode of communication with friends could not be examined due to a lack of usable data: most participants did not answer the question. It was probably because they thought it was the same question as the prior question on communication with relatives. The frequency of internet use was

Table 2 Communication-related Variables at Pretest and Posttest $(n=77)$

\begin{tabular}{|c|c|c|c|c|c|c|}
\hline & & \multicolumn{2}{|c|}{ Pretest } & \multicolumn{2}{|c|}{ Posttest } & \multirow{2}{*}{$p$ value } \\
\hline & & $n$ & $\%$ & $n$ & $\%$ & \\
\hline \multicolumn{7}{|l|}{ Own a computer } \\
\hline & Yes & 57 & 74.0 & 75 & 97.4 & \\
\hline & No & 18 & 23.4 & 0 & 0 & \\
\hline & Missing & 2 & 2.6 & 2 & 2.6 & $<.0005^{\mathrm{a}}$ \\
\hline \multicolumn{7}{|l|}{ Internet access } \\
\hline & Yes & 37 & 48.0 & 54 & 70.1 & \\
\hline & No & 17 & 22.1 & 0 & 0 & \\
\hline & Missing & 23 & 29.9 & 23 & 29.9 & $<.0005^{\mathrm{a}}$ \\
\hline \multicolumn{7}{|l|}{ Communication mode ${ }^{\mathrm{b}}$} \\
\hline & Face-to-face & 33 & 42.9 & 15 & 19.5 & \\
\hline & Mail & 7 & 9.1 & 3 & 3.9 & \\
\hline & Phone & 29 & 37.7 & 24 & 31.2 & \\
\hline & Email/Internet & 4 & 5.2 & 31 & 40.3 & \\
\hline & Missing & 4 & 5.2 & 4 & 5.2 & $<.0005^{\mathrm{a}}$ \\
\hline \multicolumn{7}{|l|}{ Internet use frequency } \\
\hline & Rare & 22 & 28.6 & 5 & 6.5 & \\
\hline & Moderate & 13 & 16.9 & 26 & 33.8 & \\
\hline & Frequent & 24 & 31.2 & 28 & 36.4 & \\
\hline & Missing & 18 & 23.4 & 18 & 23.4 & $<.00005^{\mathrm{c}}$ \\
\hline
\end{tabular}

${ }^{a}$ From a Fisher's exact test.

${ }^{b}$ Primary mode of communication with relatives.

${ }^{c}$ From a one-sided Sign test examining if the median of the differences between the pre and posttest is positive 
also similar across demographic groups with one exception: the frequency of internet use at pretest was significantly lower among those with very low income (annual income less than $\$ 5000$ ) compared to those with higher income (\$5000 or more) (results not shown). Approximately two-thirds (66.7\%) of the participants with very low income were rare users while a little over one quarter $(27.5 \%)$ of those with income $\$ 5000$ or more were rare users at pretest (results not shown).

The percentage of people who communicated with their relatives primarily through face-to-face meetings, postal mails, or phone calls decreased by $54.5,57.1$, and 17.2 per cent from the pretest to the posttest, respectively. Those who used emails or the internet as the primary communication channel increased by 675 per cent from 5.2 per cent at pretest to 40.3 per cent at posttest. The frequency of internet use also increased. The percentage of rare users considerably decreased from 28.6 per cent at pretest to 6.5 per cent at posttest, while that of moderate users doubled from 16.9 to 33.8 per cent. There was a slight increase in the percentage of frequent users from 31.2 to 36.4 per cent. A Sign test demonstrated statistically significant increases in the frequency of internet use. A one-sided Sign test showed that the median of the differences between paired observations was positive $(p<.00005)$. Those with very low income were more likely to show an increase in internet use frequency between pretest and posttest $(66.7 \%)$ than those with higher income $(30.9 \%)$ in a Fisher's exact test $(p<.005)$ (results not shown).

\section{LSNS-6 Total Score}

Table 3 compares the LSNS-6 total score at pretest and posttest and lists the scores of demographic subgroups. LSNS-6 total scores could be calculated for 72 participants who completed all LSNS-6 items at both pretest and posttest. The mean LSNS-6 total score 15.6 at pretest was slightly lower than 16.2 of an older female sample in Southern California (mean age 81) (Crooks et al., 2008) and 16.1 to 17.9 of European samples of similar ages (mean age 74) (Lubben et al., 2006). On average, the LSNS-6 total score increased by 4.1 points from pretest to post-test (Hypothesis 1). The change was statistically significant $(p<.00005)$ in both twosided paired t-test and Welch's t-test. The results from a paired t-test and a Welch's t-test were similar in terms of significance because the two groups (i.e., pretest and posttest) had the same sample size, the difference in variances between two groups was not extreme, and the total sample was not small $(n=144)$. The change was also practically significant as indicated by Glass's Delta 0.93 (confidence interval 0.57 to 1.23), which is considered large for an effect size (Maher et al. 2013). The increase is a little larger than that reported in an Israeli intervention (4.1 vs. 3.9 points) with older adults (mean age 85.9) (Isaacson et al., 2019). Sign tests indicated upward changes in the responses to individual items of the LSNS-6 scale: the median of the differences between pre-post paired observations was positive for all 6 items (pI < .00005) (results not shown). The LSNS-6 total score significantly increased from the pretest to posttest in all non-missing subgroups regardless of whether a paired t-test or a Welch's t-test was used. 
Table 3 Lubben Social Network Scale-6 Total Score at Pretest and Posttest $(n=72)$

\begin{tabular}{lcccc}
\hline & $n$ & Pretest $^{\mathrm{a}}$ & Posttest $^{\mathrm{a}}$ & $p$ value \\
\hline All & 72 & $15.6(6.3)$ & $19.7(4.3)$ & $<.00005^{\mathrm{b}}$ \\
Gender & & & & \\
Female & 46 & $16.9(5.9)$ & $20.7(3.9)$ & $<.001^{\mathrm{b}}$ \\
Male & 25 & $13.1(6.5)$ & $17.8(4.5)$ & $<.00005^{\mathrm{c}}$ \\
Missing & 1 & $21.0(0)$ & $22.0(0)$ & $-\mathrm{d}$ \\
Race & & & & \\
White & 54 & $16.3(5.5)$ & $20.0(3.9)$ & $<.0005^{\mathrm{b}}$ \\
African American & 18 & $13.5(8.1)$ & $18.8(5.3)$ & $<.00005^{\mathrm{c}}$ \\
Education & & & & \\
$<$ High school & 28 & $15.6(6.4)$ & $19.8(4.3)$ & $<.01^{\mathrm{b}}$ \\
High school or equivalent & 21 & $16.2(4.9)$ & $19.9(3.5)$ & $<.00005^{\mathrm{c}}$ \\
Some college+ & 23 & $15.1(7.4)$ & $19.4(5.1)$ & $<.00005^{\mathrm{c}}$ \\
Annual income & & & & \\
Income < \$5000 & 17 & $13.7(7.1)$ & $18.6(4.8)$ & $<.00005^{\mathrm{c}}$ \\
Income \$5000+ & 48 & $15.8(6.0)$ & $19.7(4.2)$ & $<.0005^{\mathrm{b}}$ \\
Missing & 7 & $19.3(4.7)$ & $22.6(3.5)$ & $<.005^{\mathrm{c}}$ \\
\hline
\end{tabular}

${ }^{\mathrm{a}}$ Mean (standard deviation)

${ }^{b}$ From a Welch's t-test comparing the means of the scores at pre and posttest when variances were unequal

${ }^{c}$ From a two-sided paired t-test comparing the means of the scores at pre and posttest when variances were equal

${ }^{\mathrm{d}} \mathrm{A} p$ value could not be calculated due to a lack of variability for the subgroup

The extent of social networks, measured by the LSNS-6 total score, was similar across all demographic characteristics at each pre- and posttest except for gender (results not shown). The LSNS-6 score was higher among women than men at both pretest $(p<.05)$ and posttest $(p<.01)$ in a t-test. The extent of social networks was not associated with computer ownership, internet access, or communication modes at either pretest or posttest (results not shown).

Although the extent of social networks did not vary by internet use frequency at pretest, it did at posttest (Table 4). In ANOVA, moderate users had the highest LSNS-6 total score (mean 22.1), followed by frequent users (mean 19.6) and rare users (mean 15.0) at posttest ( $p<.001$ from ANOVA) (Hypothesis 2). Pairwise comparisons using Bonferroni and Scheffé tests demonstrated a significant difference in LSNS-6 total score between moderate users and rare users $(p<.005)$ with no other pairwise differences (results not shown). In multiple linear regression, both moderate users $(p<.005)$ and frequent users $(p<.05)$ had higher LSNS-6 total scores than rare users when gender and race were controlled for (results not shown). 
Table 4 Lubben Social Network Scale-6 Total Score by Internet Use Frequency $(n=72)$

\begin{tabular}{llll}
\hline & $n$ & $\begin{array}{l}\text { Mean (stand- } \\
\text { ard deviation) }\end{array}$ & $p$ value \\
\hline Internet use frequency at pretest & & & \\
Rare user & 18 & $16.4(6.6)$ & \\
Moderate user & 13 & $18.0(4.7)$ & \\
Frequent user & 24 & $15.6(7.0)$ & \\
Missing & 17 & $13.0(5.6)$ & \\
Total & 72 & $15.6(6.3)$ & $>.05^{\mathrm{a}}$ \\
Internet use frequency at posttest & & & \\
Rare user & 5 & $15.0(2.8)$ & \\
Moderate user & 24 & $22.1(3.4)$ & \\
Frequent user & 26 & $19.6(4.8)$ & \\
Missing & 17 & $18.0(3.2)$ & \\
Total & 72 & $19.7(4.3)$ & $<.001^{\mathrm{a}}$ \\
\hline
\end{tabular}

${ }^{a}$ From analysis of variance comparing mean Lubben Social Network Scale-6 scores of 4 internet use frequency groups

\section{Variation in the Changes of the LSNS-6 Total Score by Subgroup}

Although the LSNS-6 total score increased across all subgroups, the change was significantly larger among African Americans than among Whites (Hypothesis 3). Compared to a 3.7-point increase among Whites, African Americans demonstrated a 5.3-point increase on average (Table 3). This larger improvement in social networks among African Americans than Whites remained significant even when gender was controlled for in a negative binomial regression model (incidence rate ratio (IRR) $=$ $1.45, p<.05)$ (Table 5). The result (IRR $=1.45$ ) means that African American participants are likely to improve approximately 1.45 points in the LSNS-6 total score between the pretest and posttest while White counterparts show a 1-point increase in the LSNS-6 total score regardless of gender. There was no significant difference in the change of the LSNS-6 score by each education or income level (results not shown) (Hypothesis 3).

Table 5 Results for the PrePost Change in the Lubben Social Network Scale-6 Total Score from Negative Binomial Regression $(n=71)$

\begin{tabular}{lllll}
\hline Independent variable & & $\begin{array}{l}\text { Incidence } \\
\text { rate ratio }\end{array}$ & $95 \% \mathrm{CI}$ & $p$ value \\
\hline Gender (ref: female) & Male & 1.19 & $0.90,1.57$ & $>.05$ \\
Race (ref: White) & $\begin{array}{c}\text { African- } \\
\text { Ameri- } \\
\text { can }\end{array}$ & & & \\
& & & & \\
& & & & \\
\hline
\end{tabular}

$C I$ : confidence interval 


\section{Discussion}

Our data indicate an overall positive impact of the intervention on social networks. The results demonstrate a shift in communication modes, an increase in internet use, and improved social networks among low-income older adults upon participation in an internet use promotion intervention. The primary mode of communication shifted from more traditional means such as face-to-face meetings, postal mails, and phone calls, to digital communications through the internet. The frequency of internet use significantly increased. These findings are consistent with past studies that demonstrated increased internet use for communication among older adults after training participation (Bertera et al., 2007; Damnee et al., 2019; Fields et al., 2020; Ibarra et al., 2020; Woodward et al., 2011). Hypotheses 1 and 3 were supported, and Hypothesis 2 was partially supported. The extent of social networks improved overall (Hypothesis 1), and more so among African Americans than among Whites (Hypothesis 3). Moderate and frequent internet users reported larger social networks than rare users at posttest (Hypothesis 2).

Larger social networks among moderate and frequent users than rare users at posttest seem to partially support the social augmentation thesis: this posits that internet communications expand social networks and strengthen social resources (Boase et al., 2006; Lelkes, 2013; Quan-Haase et al., 2005). The reason why it is considered partial support is that the extent of social networks did not increase linearly with an increase in the frequency of internet use. The LSNS-6 total score of moderate users (once per week or several times per week) was significantly higher than that of rare users (rarely/never or once per month), but not statistically lower than that of frequent users (once per day or more). Two factors may explain this nonlinear pattern: the imprecise measure and short-term evaluation. First, the frequency of internet use was measured using an imprecise ordinal measure that cannot gauge a precise distance between categories. Second, there was not sufficient time for the participants to become frequent users and experience the effect of this because the posttest measurement was taken within a month after training completion.

Comparatively more improvement in the extent of social networks among African Americans suggests greater benefits of such interventions for population groups of disadvantaged backgrounds. This finding is in line with a study done with European older adults (Lelkes, 2013) where the most disadvantaged groups appeared to benefit the most from internet use. In the study, internet use among older adults with lower education was associated with a greater decrease in social isolation than among those with higher education.

The larger improvement in the extent of social networks among African Americans than Whites found in our data could be related to the fact that African Americans were more likely to have very low income $(<\$ 5000)$ compared to Whites $(72.2 \%$ vs. $11.8 \%, \mathrm{p}<.001$ in Fisher's exact test) and that participants with very low income $(<\$ 5000)$ were more likely to show an increase in internet use between preand posttest than those with higher income $(66.7 \%$ vs. $30.0 \%, \mathrm{p}<.05$ in Fisher's exact test) (results not shown). When an income variable was added to the regression model for the change in LSNS-6 score, the effect of being African American 
became not significant. This suggests that having very low income partially explains why African Americans showed greater improvement in social networks than Whites.

Based on these observations, it is possible to conjecture that African American participants had limited social networks at baseline partly due to restrictions in communication (e.g., limited long distance call uses due to cost concerns). Although not statistically significant due to a small sample size, African Americans showed a tendency of having lower LSNS-6 scores than Whites (13.5 vs. 16.3) at pretest. This is similar to the studies that found smaller social networks among African Americans than Whites in the United States. (Ajrouch et al., 2001; Barnes et al., 2004; Cornwell et al., 2008).

With acquisition of computer/internet use skills and access to free broadband internet services, African American participants may have become able to communicate with their relatives and friends more freely due to an added communication channel (i.e., the internet), which in turn improved their social networks to a larger degree than among Whites. In semi-structured interviews with individuals from the same sampling pool as this study (Kim \& Gray, 2016), several respondents indicated their reticence to make long distance calls due to their limited income. Long distance phone bills were a significant burden that limited regular communication. The respondents appreciated the opportunity to communicate free-of-charge by using the internet access offered in the intervention (Kim \& Gray, 2016).

\section{Limitations}

Several study limitations should be noted. As stated previously, the authors conducted a post hoc evaluation without involvement in study design or data collection, and therefore could not influence the study design. Due to the lack of a control group, comparisons could not be made between those who had and had not completed the intervention. Long-term effects could not be evaluated given the posttest was given within one month after the completion of the computer/internet skills training. The generalizability of the results may be limited because our results are based on a small number of programme participants who were living in multi-unit public housing buildings in a specific geographic area. The participants are likely to be healthier, without severe disabilities, and more proactive than non-participants since they volunteered to participate. The living environment itself (i.e., multi-unit public housing buildings) where the participants could practice and apply what they have learned together may have affected the outcomes in a positive way. The study's small sample size limited the number of variables that could be controlled in regression analysis, and sizable missing cases in some variables (i.e., income, internet access status, internet use frequency) prohibited an understanding of the whole picture. 


\section{Implications}

Our findings point to a few issues to consider in planning intervention programmes to encourage internet use among low-income older adults and to improve social connectedness. Given the positive impact of the multi-component intervention on low-income older adults' social networks, programmes targeting similar population groups should provide access to free computer devices and seamless internet connectivity as well as internet skills training as standard protocol. A related qualitative study (Kim \& Gray, 2016) demonstrated the value of computer and internet skills training in helping participants connect through the internet with the relatives and friends who previously could not be reached. The study also indicated the importance of providing free individual devices and internet access in promoting continued internet use, particularly for low-income groups (Kim \& Gray, 2016).

Additionally, low-income older adults may need support in order to develop and sustain both online and in-person networks. A study using longitudinal analyses (Shklovski et al., 2004) suggests that in-person contact tends to be more critical than internet communications in maintaining social networks. The study demonstrated that in-person contact led to more internet communications (i.e., more emails), but emails did not induce more phone calls or in-person visits (Shklovski et al., 2004). Subsequently, in addition to supporting low-income older adults to expand and deepen their social networks through online modalities, such individuals should be aided in developing and maintaining in-person connections (e.g., through social services). In this fashion, both modes of social support can bolster each other. For example, while in-person social support can allow for instrumental support (e.g., assistance with transportation), online social support can improve frequency of contact (e.g., contact via email, instant chat, and Skype-type programmes) (Shklovski et al., 2004).

It is important to add that the internet provides much more than social networking. It is a portal to conduct transactions (e.g., shopping, banking), as well as to search for information and entertainment, among other things. The participants in this study, however, tend to be much more conservative in their use of the internet, compared to that of the general population. In a related study, the authors found that such participants encountered many barriers in internet use, for various reasons, such as fear of technology, fear of or misconceptions about cyber security, and low literacy (Kim \& Gray, 2016).

In order to follow-up on this study's findings, future research is needed with a larger and more diverse sample, conducted over a longer time period to assess the sustainability of internet use and its impact on social networks and applicability of our findings to other population groups. To examine the retention of regular internet use as well as to what extent participants' social networks are expanded, follow-up data collection beyond a posttest at training completion, such as those at 6 and 12 months, will be needed.

The research also will need to examine how older adults of different income groups and in different living arrangements respond to an internet use promotion intervention with regard to the extent of social networks. Since this study's 
intervention was conducted in a multi-unit public housing setting, there was little variation in income and programme participants had opportunities to interact with other participants in the building. Due to the narrow income range, the difference in improvement of social networks by income level could not be properly tested. Their living arrangement (i.e., living in a multi-unit building) also could have acted as a confounder in affecting social networks. In addition to increased digital communication, learning and applying the skills in a group setting itself could have improved social networks (Werner et al., 2011; White et al., 2002).

\section{Declarations}

Ethical Statement The study was approved by the institutional review board of Northern Illinois University (No. HS10-0449).

Conflict of Interest The authors declare that there is no conflict of interest.

Informed Consent Informed consent was obtained from study participants after the purposes of the study and the procedures involved in participation were explained.

Ethical Treatment of experimental subject (Animal and Human) All procedures performed in studies involving human participants were in accordance with the ethical standards of the institutional and/or national research committee (University Institutional Review Board, \#HS10-0449) and with the 1964 Helsinki declaration and its later amendments or comparable ethical standards.

\section{References}

Ajrouch, K. J., Antonucci, T. C., \& Janevic, M. R. (2001). Social networks among blacks and whites: the interaction between race and age. The Journals of Gerontology: Series B, Psychological Sciences and Social Sciences, 56(2), S112-S118. https://doi.org/10.1093/geronb/56.2.s112

Aggarwal, B., Xiong, Q., \& Schroeder-Butterfill, E. (2020). Impact of the use of the internet on quality of life in older adults: review of literature. Primary Health Care Research and Development, 21(e55), 1-6. https://doi.org/10.1017/S1463423620000584

Anderson, M., \& Perrin, A. (2017, May 17). Tech adoption climbs among older adults. Pew Research Center. http://www.pewinternet.org/2017/05/17/tech-adoption-climbs-among-older-adults/

Banbury, A., Chamberlain, D., Nancarrow, S., Dart, J., Gray, L., \& Parkinson, L. (2017). Can videoconferencing affect older people's engagement and perception of their social support in long-term conditions management: A social network analysis from the Telehealth Literacy Project. Health \& Social Care in the Community, 25(3), 938-950. https://doi.org/10.1111/hsc.12382

Barnes, L. L., Mendes de Leon, C. F., Bienias, J. L., \& Evans, D. A. (2004). A longitudinal study of Black-White differences in social resources. The Journals of Gerontology: Series B, Psychological Sciences and Social Sciences, 59(3), S146-S153. https://doi.org/10.1093/geronb/59.3.S146

Berkowsky, R. W., Cotten, S. R., Yost, E. A., \& Winstead, V. P. (2013). Attitudes towards and limitations to ICT use in assisted and independent living communities: Findings from a specially-designed technological intervention. Educational Gerontology, 39(11), 797-811. https://doi.org/10.1080/ 03601277.2012.734162

Bertera, E. M., Bertera, R. L., Morgan, R., Wuertz, E., \& Attey, A. M. O. (2007). Training older adults to access health information. Educational Gerontology, 33(6), 483-500. https://doi.org/10.1080/ 03601270701328250 
Bessière, K., Kiesler, S., Kraut, R. E., \& Boneva, B. (2008). Effects of internet use and social resources on changes in depression. Information, Communication \& Society, 11(1), 47-70. https://doi.org/10. 1080/13691180701858851

Bessière, K., Pressman, S., Kiesler, S., \& Kraut, R. (2010). Effects of internet use on health and depression: A longitudinal study. Journal of Medical Internet Research, 12(1), e6. https://doi.org/10.2196/jmir.1149

Billipp, S. H. (2001). The psychosocial impact of interactive computer use within a vulnerable elderly population: A report on a randomized prospective trial in a home health care setting. Public Health Nursing, 18(2), 138-145. https://doi.org/10.1046/j.1525-1446.2001.00138.x

Boase, J., Horrigan, J. B., Wellman, B., \& Rainie, L. (2006, January 25). The strength of internet ties: The internet and email aid users in maintaining their social networks and provide pathways to help when people face big decisions. Pew Internet and American Life Project. https://www.pewresearch. org/internet/wp-content/uploads/sites/9/media/Files/Reports/2006/PIP_Internet_ties.pdf.pdf

Broady, T., Chan, A., Caputi, P., \& Broady, T. R. (2010). Comparison of older and younger adults' attitudes towards and abilities with computers: Implications for training and learning. British Journal of Educational Technology, 41, 473-485. https://doi.org/10.1111/j.1467-8535.2008.00914.x

Burholt, V., Windle, G., Gott, M., Morgan, D. J. on behalf of the CFAS Wales team. (2020). Technologymediated communication in familial relationships: Moderated-mediation models of isolation and loneliness. The Gerontologist, 60(7), 1202-1212. https://doi.org/10.1093/geront/gnaa040

Campbell, R. J. (2008). Meeting seniors' information needs: Using computer technology. Home Health Care Management Practice, 20(4), 328-335. https://doi.org/10.1177/1084822307310765

Carpenter, B. D., \& Buday, S. (2007). Computer use among older adults in a naturally occurring retirement community. Computers in Human Behavior, 23, 3012-3024. https://doi.org/10.1016/j.chb.2006.08.015

Chang, Q., Sha, F., Chan, C. H., \& Yip, P. (2018). Validation of an abbreviated version of the Lubben Social Network Scale ("LSNS-6") and its associations with suicidality among older adults in China. PloS One, 13(8), e0201612. https://doi.org/10.1371/journal.pone.0201612

Chen, K., \& Chan, A. (2011). A review of technology acceptance by older adults. Gerontechnology, 10, 1. https://doi.org/10.4017/gt.2011.10.01.006.00

Chen, Y. R., \& Schulz, P. J. (2016). The effect of information communication technology interventions on reducing social isolation in the elderly: A systematic review. Journal of Medical Internet Research, 18(1), e18. https://doi.org/10.2196/jmir.4596

Choi, M., Kong, S., \& Jung, D. (2012). Computer and internet interventions for loneliness and depression in older adults: A meta-analysis. Healthcare Informatics Research, 18, 191-198. https://doi.org/10. 4258/hir.2012.18.3.191

Choi, N. G., \& DiNitto, D. M. (2013). The digital divide among low-income homebound older adults: Internet use patterns, eHealth literacy, and attitudes toward computer/internet use. Journal of Medical Internet Research, 15(5), e93. https://doi.org/10.2196/jmir.2645

Coreil, J. (2010). Social and behavioral foundations of public health. Sage.

Cornwell, B., Laumann, E. O., \& Schumm, L. P. (2008). The social connectedness of older adults: A national profile. American Sociological Review, 73, 185-203. https://doi.org/10.1177/000312240807300201

Cotten, S. R., Ford, G., Ford, S., \& Hale, T. M. (2014). Internet use and depression among retired older adults in the United States: A longitudinal analysis. The Journals of Gerontology Series B: Psychological Sciences and Social Sciences, 69, 763-771. https://doi.org/10.1093/geronb/gbu018

Crooks, V. C., Lubben, J., Petitti, D. B., Little, D., \& Chiu, V. (2008). Social network, cognitive function, and dementia incidence among elderly women. American Journal of Public Health, 98(7), 1221-1227. https://doi.org/10.2105/AJPH.2007.115923

Cummings, J., Butler, B., \& Kraut, R. (2002). The quality of online social relationships. Communications of the ACM, 45, 103-108. https://doi.org/10.1145/514236.514242

Czaja, S. J., Boot, W. R., Charness, N., Rogers, W. A., \& Sharit, J. (2018). Improving social support for older adults through technology: Findings from the prism randomized controlled trial. The Gerontologist, 58(3), 467-477. https://doi.org/10.1093/geront/gnw249

Czaja, S. J., \& Lee, C. C. (2007). The impact of aging on access to technology. Universal Access in the Information Society, 5, 341-349. https://doi.org/10.1007/s10209-006-0060-X

Damnée, S., Djabelkhir-Jemmi, L., Ware, C., Benovici, J., Kerhervé, H., Lewis, M., Rigaud, A., \& Wu, Y. (2019). Exploring the impact of a group-based tablet-PC training program in older adults. Geriatrie et Psychologie Neuropsychiatrie du Vieillissement, 17(3), 336-342. https://doi.org/10.1684/pnv.2019.0802

Dickinson, A., \& Gregor, P. (2006). Computer use has no demonstrated impact on the well-being of older adults. International Journal of Human-Computer Studies, 64(8), 744-753. https://doi.org/10. 1016/j.ijhcs.2006.03.001 
DiMaggio, P., Hargittai, E., Celeste, C., \& Shafer, S. (2004). Digital inequality from unequal access to differentiated use. In K. M. Neckerman (Ed.), Social inequality (pp. 355-400). Russell Sage Foundation.

Fields, J., Cemballi, A., Michalec, C., Uchida, D., Griffiths, K., Cardes, H., Cuellar, J., Chodos, A., \& Lyles, C. (2020). In-home technology training among socially isolated older adults: Findings from the Tech Allies Program. Journal of Applied Gerontology, 40(5), 489-499. https://doi.org/10.1177/0733464820910028

Forsman, A. K., \& Nordmyr, J. (2017). Psychosocial links between internet use and mental health in later life: A systematic review of quantitative and qualitative evidence. Journal of Applied Gerontology, 36(12), 1471-1518. https://doi.org/10.1177/0733464815595509

Friemel, T. N. (2016). The digital divide has grown old: Determinants of a digital divide among seniors. New Media and Society, 18(2), 313-331. https://doi.org/10.1177/1461444814538648

Gardiner, C., Geldenhuys, G., \& Gott, M. (2018). Interventions to reduce social isolation and loneliness among older people: An integrative review. Health \& Social Care in The Community, 26(2), 147-157. https://doi.org/10.1111/hsc. 12367

Gatto, S. L., \& Tak, S. H. (2008). Computer, internet, and e-mail use among older adults: Benefits and barriers. Educational Gerontology, 34, 800-811. https://doi.org/10.1080/03601270802243697

Gray, J., Kim, J., Ciesla, J. R., \& Yao, P. (2016). Rasch analysis of the Lubben Social Network Scale-6 (LSNS6). Journal of Applied Gerontology, 35(5), 508-528. https://doi.org/10.1177/0733464814560468

Grossman, L. V., Creber, R. M. M., Ancker, J. S., Ryan, B., Polubriaginof, F., Qian, M., Alarcon, I., Restaino, S., Bakken, S., Hripcsak, G., \& Vawdrey, D. K. (2019). Technology access, technical assistance, and disparities in inpatient portal use. Applied Clinical Informatics, 10(1), 40-50. https://doi.org/10.1055/s-0038-1676971

Hald, A. (2003). A history of probability and statistics and their applications before 1750. Wiley.

Hawthorne, G. (2006). Measuring social isolation in older adults: Development and initial validation of the friendship scale. Social Indicators Research, 77(3), 521-548. https://doi.org/10.1007/ s11205-005-7746-y

Ialongo, C. (2016). Understanding the effect size and its measures. Biochemia Medica, 26(2), 150-163. https://doi.org/10.11613/BM.2016.015

Ibarra, F., Baez, M., Cernuzzi, L., \& Casati, F. (2020). A systematic review on technology-supported interventions to improve old-age social wellbeing: Loneliness, social isolation, and connectedness. Journal of Healthcare Engineering, 2020, 2036842. https://doi.org/10.1155/2020/2036842

Isaacson, M., Cohen, I., \& Shpigelman, C. N. (2019, March 25). Leveraging emotional wellbeing and social engagement of the oldest old by using advanced communication technologies: A pilot study using Uniper-Care's technology. Proceedings of the 3rd IET International Conference on Technologies for Active and Assisted Living, London, UK. https://doi.org/10.1049/cp.2019.0102

Jang, Y., Powers, D. A., Park, N. S., Chiriboga, D. A., Chi, I., \& Lubben, J. (2020). Performance of an abbreviated Lubben Social Network Scale (LSNS-6) in three ethnic groups of older Asian Americans, The Gerontologist, gnaa156. https://doi.org/10.1093/geront/gnaa156

Jung, Y., Peng, W., Moran, M., Jin, S. A., McLaughlin, M., Cody, M., Jordan-Marsh, M., Albright, J., \& Silverstein, M. (2010). Low income minority seniors' enrollment in a cybercafe: Psychological barriers to crossing the digital divide. Educational Gerontology, 36, 193-212. https://doi.org/10. $1080 / 03601270903183313$

Kaye, H. S. (2000). Disability and the digital divide. Disability Statistics Abstract, 22, 1-4.

Kim, J., \& Gray, J. (2016). Qualitative evaluation of an intervention program for sustained internet use among low-income older adults. Ageing International, 41(3), 240-253. https://doi.org/10.1007/ s12126-015-9235-1

Kim, Y. S. (2008). Reviewing and critiquing computer learning and usage among older adults. Educational Gerontology, 34, 709-735. https://doi.org/10.1080/03601270802000576

Kraut, R., Kiesler, S., Boneva, B., Cummings, J., Helgeson, V., \& Crawford, A. (2002). Internet paradox revisited. Journal of Social Issues, 58, 49-74.

Kraut, R., Lundmark, V., Patterson, M., Kiesler, S., Mukopadhyay, T., \& Scherlis, W. (1998). Internet paradox: A social technology that reduces social involvement and psychological well-being? American Psychologist, 53, 1017-1031. https://doi.org/10.1037/0003-066X.53.9.1017

Lelkes, O. (2013). Happier and less isolated: Internet use in old age. Journal of Poverty \& Social Justice, 21(1), 33-46. https://doi.org/10.1332/175982713X664047

Livingston, G. (2019, July 3). On average, older adults spend over half their waking hours alone. Pew Research Center. https://www.pewresearch.org/fact-tank/2019/07/03/on-average-olderadults-spend-over-half-their-waking-hours-alone/ 
Loges, W. E., \& Jung, J. (2001). Exploring the digital divide: Internet connectedness and age. Communication Research, 28, 536-563. https://doi.org/10.1177/009365001028004007

Long, S. J., \& Freese, J. (2001). Regression models for categorical dependent variables using Stata. Stata Press.

Lorence, D. P., Park, H., \& Fox, S. (2006). Racial disparities in health information access: Resilience of the digital divide. Journal of Medical Systems, 30(4), 241-249. https://doi.org/10.1007/ s10916-005-9003-y

Lubben, J., Blozik, E., Gillmann, G., Iliff, S., Kruse, W. V. R., Beck, J. C., \& Stuck, A. E. (2006). Performance of an abbreviated version of the Lubben Social Network Scale among three European community-dwelling older adult populations. The Gerontologist, 46(4), 503-513. https://doi.org/ 10.1093/geront/46.4.503

Lubben, J. E. (1988). Assessing social networks among elderly populations. Family \& Community Health, 11(3), 42-52. https://doi.org/10.1097/00003727-198811000-00008

Lubben, J. E., \& Gironda, M. W. (2000). Social support networks. In D. Osterweil, K. Brummel-Smith, \& J. Beck (Eds), Comprehensive geriatric assessment (pp. 121-137). McGraw-Hill.

Ma, Q., Chan, A., \& Teh, P. (2020). Bridging the digital divide for older adults via observational training: Effects of model identity from a generational perspective. Sustainability, 12(11), 4555. https://doi. org/10.3390/su12114555

Macdonald, B., \& Hulur, G. (2021). Internet adoption in older adults: Findings from the Health and Retirement Study. Cyberpsychology, Behavior, and Social Networking, 24(2), 101-107. https://doi. org/10.1089/cyber.2019.0736

Maher, J. M., Markey, J. C., \& Ebert-May, D. (2013). The other half of the story: Effect size analysis in quantitative research. CBE Life Sciences Education, 12(3), 345-351. https://doi.org/10.1187/cbe. 13-04-0082

Mather, M., Jacobsen, L. A., \& Pollard, K. M. (2015). Aging in the United States. Population Bulletin, $70,1-23$.

Mather, M., Scommegna, P., \& Kilduff, L. (2019, July 15). Aging in the United States. Population Reference Bureau. https://www.prb.org/aging-unitedstates-fact-sheet/

Mehta, C. R., \& Patel, N. R. (1983). A network algorithm for performing Fisher's exact test in r x c contingency tables. Journal of the American Statistical Association, 78, 427-434. https://doi.org/10. $2307 / 2288652$

Mellor, D., Firth, L., \& Moore, K. (2008). Can the internet improve the well-being of the elderly? Ageing International, 32, 25-42. https://doi.org/10.1007/s12126-008-9006-3

Mitchell, U. I., Chebli, P. G., Ruggerio, L., \& Muramatsu, N. (2019). The digital divide in health-related technology use: The significance of race/ethnicity. The Gerontologist, 59(1), 6-14. https://doi.org/ 10.1093/geront/gny138

Morton, T. A., Wilson, N., Haslam, C., Birney, M., Kingston, R., \& McCloskey, L. G. (2018). Activating and guiding the engagement of seniors with online social networking: Experimental findings from the AGES 2.0 Project. Journal of Aging and Health, 30(1), 27-51. https://doi. org/10.1177/0898264316664440

Myagmarjav, S., Burnette, D., \& Goeddeke, F. (2019). Comparison of the 18-item and 6-item Lubben Social Network Scales with community-dwelling older adults in Mongolia. PloS One, 14(4), e0215523. https://doi.org/10.1371/journal.pone.0215523

Myhre, J. W., Mehl, M. R., \& Glisky, E. L. (2017). Cognitive benefits of online social networking for healthy older adults. The Journals of Gerontology Series B Psychological Sciences and Social Sciences, 72(5), 752-760. https://doi.org/10.1093/geronb/gbw025

Nahm, E., \& Resnick, B. (2001). Homebound older adults' experiences with the internet and email. Computers in Nursing, 19, 257-263.

Nahm, E., Resnick, B., \& Gaines, J. (2004). Testing the reliability and validity of computer-mediated social support measures among older adults. CIN: Computers, Informatics, Nursing, 22(4), 211219. https://doi.org/10.1097/00024665-200407000-00009

Nakagomi, A., Shiba, K., Kondo, K., Kawachi, I. (2020). Can online communication prevent depression among older people? A longitudinal analysis Journal of Applied Gerontology, 2020 Dec 24;733464820982147. https://doi.org/10.1177/0733464820982147

Neves, B. B., Franz, R., Judges, R., Beermann, C., \& Baecker, R. (2019). Can digital technology enhance social connectedness among older adults? A feasibility study. Journal of Applied Gerontology, 38(1), 49-72. https://doi.org/10.1177/0733464817741369 
Nie, N. H. (2001). Sociability, interpersonal relations, and the internet reconciling conflicting findings. American Behavioral Scientist, 45, 420-435. https://doi.org/10.1177/00027640121957277

Nie, N. H., \& Hillygus, D. S. (2002). The impact of internet use on sociability: Time-diary findings. IT \& Society, 1(1), 1-20.

Olsson, T., Samuelsson, U., \& Viscovi, D. (2019). Resources and repertoires: Elderly online practices. European Journal of Communication, 34(1), 38-56. https://doi.org/10.1177/0267323118810852

Pew Research Center. (2021, April 7). Internet/broadband fact sheet. http://www.pewinternet.org/fact-sheet/ internet-broadband/

Quan-Haase, A., Wellman, B., Witte, J., \& Hampton, K. (2005). Capitalizing on the net: Social contact, civil engagement, and sense of community. In B. Wellman \& C. Haythornthwaite (Eds), The internet in everyday life (pp. 289-324). Blackwell Publishers, Ltd.

Rosenthal, R. L. (2008). Older computer-literate women: Their motivations, obstacles, and paths to success. Educational Gerontology, 34(7), 610-626. https://doi.org/10.1080/03601270801949427

Ruxton, G. D. (2006) The unequal variance t-test is an underused alternative to Student's t-test and the Mann-Whitney U test. Behavioral Ecology, 17, 688-690. https://doi.org/10.1093/beheco/ark016

Sansoni, J., Marosszeky, N., Sansoni, E., \& Fleming, G. (2010). Final report: Effective assessment of social isolation. Centre for Health Service Development, University of Wollongong, Australia. http://www.adhc.nsw.gov.au/_data/assets/file/0007/236329/24_Social_Isolation_Report.pdf

Savin, N. E. (1980). The Bonferroni and the Scheffé multiple comparison procedures. The Review of Economic Studies, 47(1), 255-273. https://doi.org/10.2307/2297112

Sayago, S., Forbes, P., \& Blat, J. (2013). Older people becoming successful ICT learners over time: Challenges and strategies through an ethnographical lens. Educational Gerontology, 39(7), 527-544. https://doi.org/10.1080/03601277.2012.703583

Seifart, A., Cotten, S. R., \& Xie, B. (2021). A double burden of exclusion: Digital and social exclusion of older adults in times of COVID-19. The Journals of Gerontology Series B Psychological Sciences and Social Sciences, 76(3), e99-e103. https://doi.org/10.1093/geronb/gbaa098

Shklovski, I., Kraut, R., \& Rainie, L. (2004). The internet and social participation: Contrasting crosssectional and longitudinal analyses Journal of Computer Mediated Communication, 10(1), JCMC1018. https://doi.org/10.1111/j.1083-6101.2004.tb00226.x

Slegers, K., Boxtel, M. P., \& Jolles, J. (2008). Effects of computer training and internet usage on the well-being and quality of life of older adults: A randomized, controlled study. Journal of Gerontology, Series B, Psychological Sciences \& Social Sciences, 63(3), 176-184. https://doi.org/ 10.1093/geronb/63.3.P176

Smith, A. (2014a, January 6). African Americans and technology use. Pew Research Center. https://www. pewresearch.org/internet/2014/01/06/african-americans-and-technology-use/

Smith, A. (2014b, April 3). Older adults and technology use. Pew Research Center. https://www. pewresearch.org/internet/2014/04/03/older-adults-and-technology-use/

StataCorp. (2011a). Stata 12 base reference manual. Stata Press.

StataCorp. (2011b). Stata statistical software (Version 12). StataCorp LLC. https://www.stata.com/products/

Sum, S., Mathews, R. M., Hughes, I., \& Campbell, A. (2008). Internet use and loneliness in older adults. Cyberpsychology and Behavior, 11(2), 208-211. https://doi.org/10.1089/cpb.2007.0010

Szabo, A., Allen, J., Stephens, C., \& Alpass, F. (2019). Longitudinal analysis of the relationship between purposes of internet use and well-being among older adults. The Gerontologist, 59(1), 58-68. https://doi.org/10.1093/geront/gny036

van der Wardt, V., Bandelow, S., \& Hogervorst, E. (2012). The relationship between cognitive abilities, well-being and use of new technologies in older people. Gerontechnology, 10(4), 187-207. https://doi.org/10.4017/gt.2012.10.4.001.00

Wagner, N., Hassanein, K., \& Head, M. (2010). Computer use by older adults: A multi-disciplinary review. Computers in Human Behavior, 26, 870-882. https://doi.org/10.1016/j.chb.2010.03.029

Weiser, E. B. (2001). The functions of internet use and their social and psychological consequences. CyberPsychology \& Behavior, 4, 723-743. https://doi.org/10.1089/109493101753376678

Wellman, B., Haase, A. Q., Witte, J., \& Hampton, K. (2001). Does the internet increase, decrease, or supplement social capital? American Behavioral Scientist, 45, 436-455. https://doi.org/10. 1177/00027640121957286

Werner, J. M., Carlson, M., Jordan-Marsh, M., \& Clark, F. (2011). Predictors of computer use in community-dwelling, ethnically diverse older adults. Human Factors, 53(5), 431-447. https:// doi.org/10.1177/0018720811420840 
White, C. M., Gummerum, M., Wood, S., \& Hanoch, Y. (2017). Internet safety and the silver surfer: The relationship between gist reasoning and adults' risky online behavior. Journal of Behavioral Decision Making, 30(4), 819-827. https://doi.org/10.1002/bdm.2003

White, H., McConnell, E., Clipp, E., Branch, L. G., Sloane, R., Pieper, C., \& Box, T. L. (2002). A randomized controlled trial of the psychosocial impact of providing internet training and access to older adults. Aging \& Mental Health, 6(3), 213-221. https://doi.org/10.1080/13607860220142422

Winstead, V., Anderson, W. A., Yost, E. A., Cotten, S. R., Warr, A., \& Berkowsky, R. W. (2013). You can teach an old dog new tricks: A qualitative analysis of how residents of senior living communities may use the web to overcome spatial and social barriers. Journal of Applied Gerontology, 32(5), 540-560. https://doi.org/10.1177/0733464811431824

Woodward, A., Freddolino, P., Blaschke-Thompson, C., Wishart, D., Bakk, L., Kobayashi, R., \& Caitlin, T. (2011). Technology and aging Project: Training outcomes and efficacy form randomized field trial. Ageing International, 36, 46-65. https://doi.org/10.1007/s12126-010-9074-z

Xie, B., \& Bugg, J. M. (2009). Public library computer training for older adults to access high-quality internet health information. Library \& Information Science Research, 31(3), 155. https://doi.org/ 10.1016/j.lisr.2009.03.004

Yoon, H., Jang, Y., Vaughan, P. W., \& Garcia, M. (2020). Older adults' internet use for health information: Digital divide by race/ethnicity and socioeconomic status. Journal of Applied Gerontology, 39(1), 105-110. https://doi.org/10.1177/0733464818770772

Yu, K., Wu, S., \& Chi, I. (2021). Internet use and loneliness of older adults over time: The mediating effect of social contact. The Journals of Gerontology: Series B, 76(3), 541-550. https://doi.org/10. 1093/geronb/gbaa004

Zickuhr, K., \& Madden, M. (2012, June 6). Older adults and internet use. Pew Research Center. https:// www.pewresearch.org/internet/2012/06/06/older-adults-and-internet-use/

Zickuhr, K., \& Smith, A. (2012, April 13). Digital difference. Pew Research Center. https://www. pewresearch.org/internet/2012/04/13/digital-differences/

Zimmerman, D. W. (2004). A note on preliminary tests of equality of variances. British Journal of Mathematical and Statistical Psychology, 57, 173-181. https://doi.org/10.1348/000711004849222

Publisher's Note Springer Nature remains neutral with regard to jurisdictional claims in published maps and institutional affiliations.

Jinsook Kim PhD, MPH, DDS, Is a Professor of the School of Health Studies at Northern Illinois University. Dr. Kim's research interests include health promotion interventions for older adults focused on social connectedness, palliative care training for direct care workers who care for people with intellectual and developmental disabilities and older adults, and stress management for health care workers using digital and mobile technologies.

Jennifer Gray PhD, MPP Is an Associate Professor of the School of Health Studies at Northern Illinois University. Dr. Gray's research interestsinclude health promotion for older adults and people with disabilities, including an examination of the effects of social support. She focuses on stress management and palliative care training of direct care workers in the intellectual and developmental disability and longterm care service systems.

James R. Ciesla PhD Is the Dean of the College of Health and Human Services at Bowling Green State University. Dr. Ciesla's research focuses on ways to measure and evaluate the outcomes of health services through the application of human capital economics.

Ping Yao PhD Is an Associate Professor of the School of Health Studies at Northern Illinois University. Dr. Yao's research interests include biostatistics and statistical application in medical and health research. 


\section{Authors and Affiliations}

\section{Jinsook Kim ${ }^{1}$ (D) Jennifer A. Gray ${ }^{1}$. James R. Ciesla ${ }^{2}$. Ping Yao ${ }^{1}$}

Jennifer A. Gray

j-gray@niu.edu

James R. Ciesla

jciesla@bgsu.edu

Ping Yao

pyao@niu.edu

1 School of Health Studies, Northern Illinois University, Wirtz Hall 254, DeKalb, Illinois 60115, USA

2 College of Health and Human Services, Bowling Green State University, 105 Health and Human Services Building, Bowling Green, $\mathrm{OH} 43403$, USA 